Témoigner Témoigner. Entre histoire et mémoire

Getuigen Revue pluridisciplinaire de la Fondation Auschwitz

$126 \mid 2018$

Questions sur l'avenir du travail de mémoire

\title{
Hero worship at all costs?
}

The dispute over the Museum of the Second World War in Gdansk

\section{Martin Sander}

Translator. Elisabeth Tutschek

\section{(2) OpenEdition}

\section{Journals}

Electronic version

URL: https://journals.openedition.org/temoigner/7458

DOI: 10.4000/temoigner.7458

ISSN: 2506-6390

\section{Publisher:}

Éditions du Centre d'études et de documentation Mémoire d'Auschwitz, Éditions Kimé

Printed version

Date of publication: 2 April 2018

Number of pages: $124-130$

ISBN: 978-2-930953-06-9

ISSN: 2031-4183

\section{Electronic reference}

Martin Sander, "Hero worship at all costs?", Témoigner. Entre histoire et mémoire [Online], 126 | 2018, Online since 24 January 2022, connection on 04 February 2022. URL: http://journals.openedition.org/ temoigner/7458 ; DOI: https://doi.org/10.4000/temoigner.7458 


\section{Herinneringsplek}

\section{'JE HEBT NIETS GEZIEN...' IN DOUADIC}

\section{Langsheen de D17, in Douadic.}

In het departement Indre, langs de D17 die van de stad Blanc naar het Huis van het Regionaal natuurpa van de Brenne leidt, aan de uitgang van het dorp Douadic, bereikt men een omheinde weide. De plek heet L'tang du Blanc. Ooit bevond zich er een helemaal in de vergetelheid is geraals de vergetelheid is geraakt. Je hebt niets

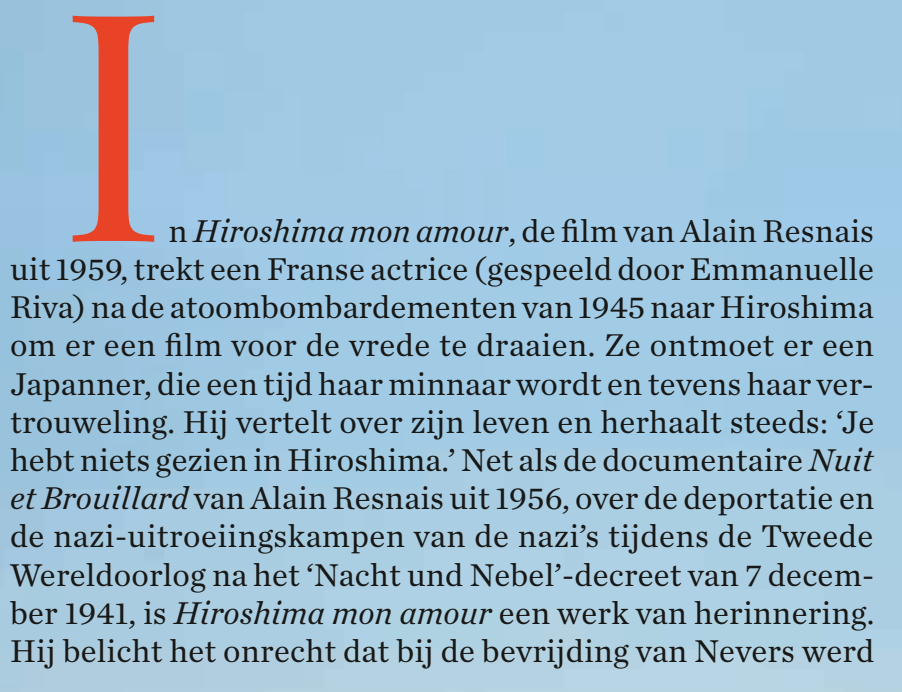

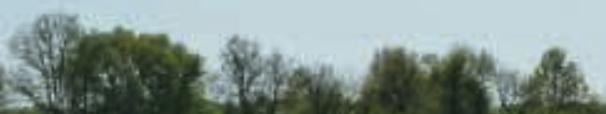

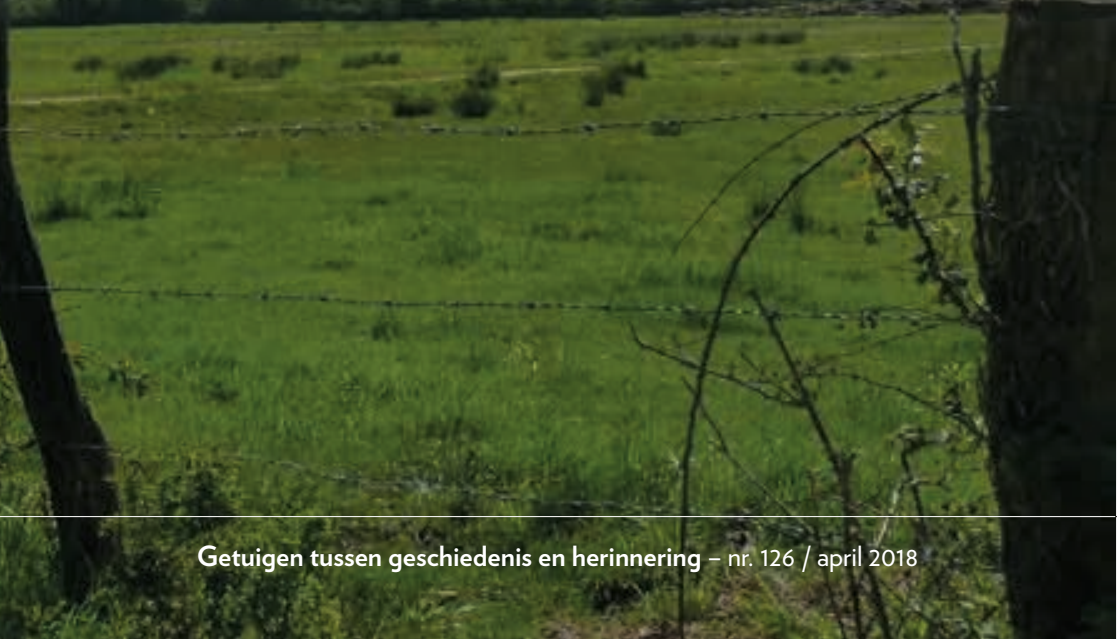

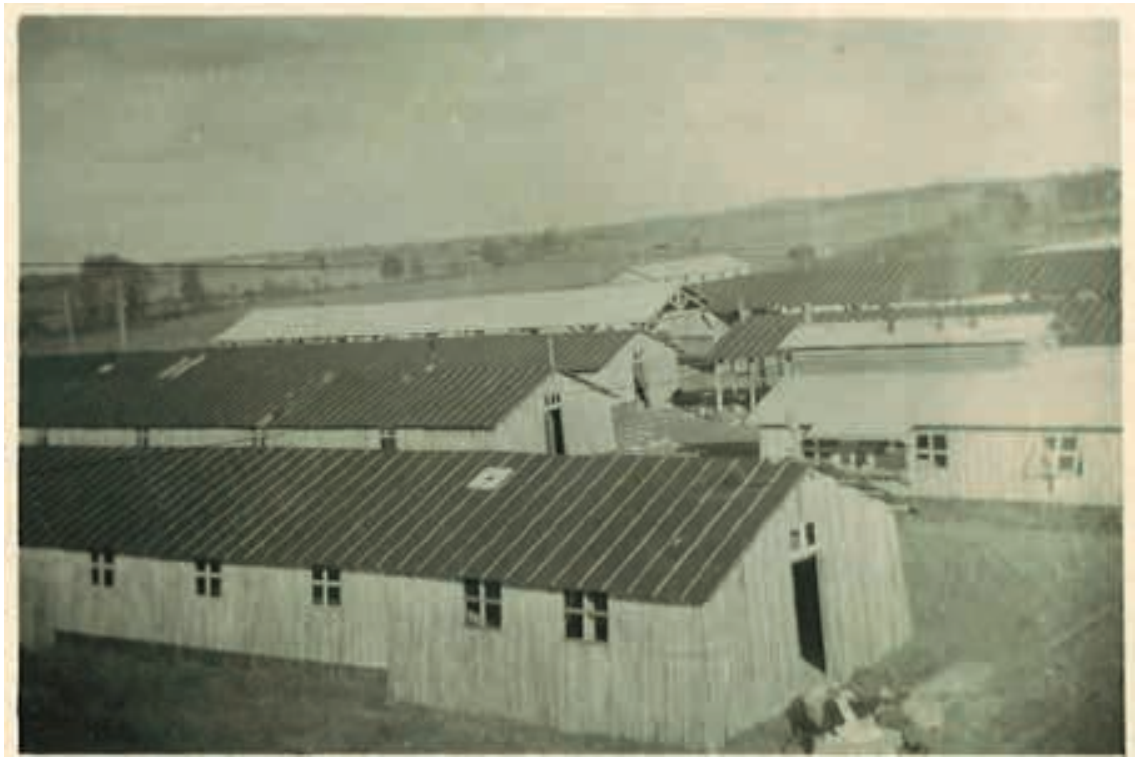

aangedaan aan de dode Duitse soldaat en de kaalgeschoren Française, die verliefd was geworden op een Duitser, ook allikit dit alles onbeduide de gewornen van Hiroshina. De film onderstreept ook het grote verschil de bezus le bezetting en de bevrijding) en een Hiroshima twee minneers in Nevers). Hiroshina, tweeninnass in Nevers). Hiroshima mon amour wil meer doen wijstop de onmogelijkheidodn. wen over Hiroshima en ondes het verschil tush en onderstreept liteit en de weergave ervan in fictie of liteit en de weergave ervan in fictie of Duras, auteur van het scenarite Duras, auteur wan het scenario en de lijkheden van de media (van de fleghetbijzen van de media (van de film in hetijzin over een gebeurtenis, een catastrofe,

een vernietiging. De film aarzelt tussen etuigenis en reconstructie. Uiteindelijk ligt de nadruk voornamelijk op econstructie als het uitgelezen instrument om te herinneren, en dus ook om tertellen. In het geval van Douadic blijken herinneringsoverdracht en historisch onderzoek noodzakelijk om betekenis te geven aan een plek zonder sporen.

\section{HET KAMP YAN DOUADIC}

In het begin was Douadic een kamp vor Duitse gevangenen (1939-1940), in november 1940 werd het veriif vor vreendelingen (onder erijf voor wreendelingen (onder telinespan in aurus 1942 eentelingen) en in augustus 1942 een verdie werden gevangengenomen in het die werden gevergengen

Het kamp van Douadic wordt dus in 


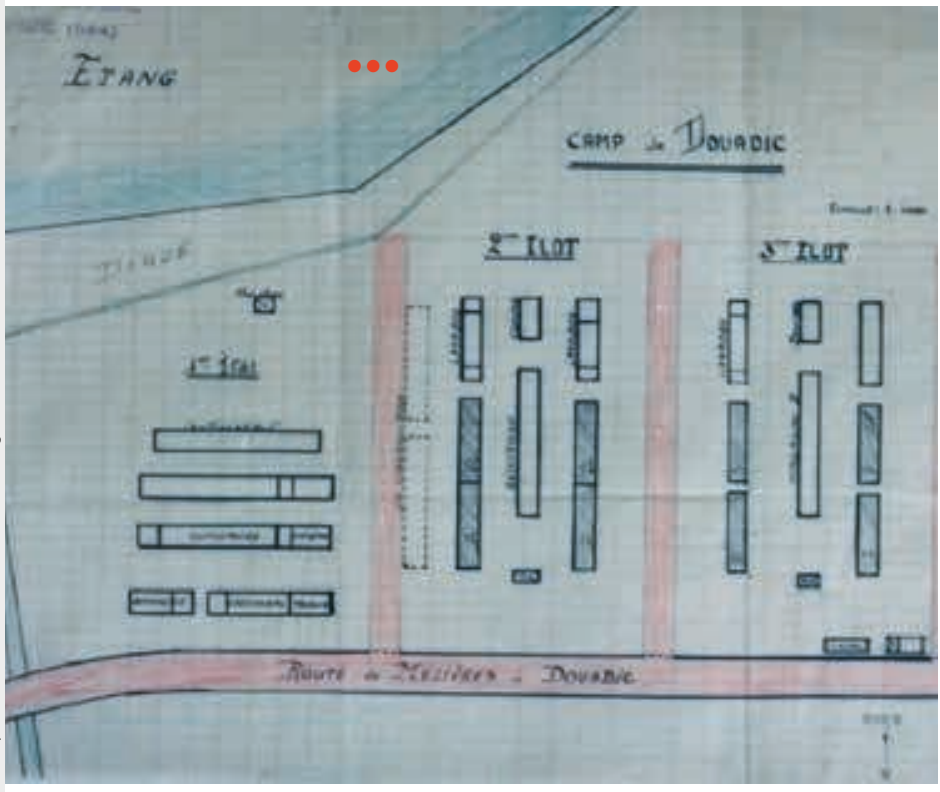

Plan van

het kamp van

Douadic kort na de

bevrijding van de

en vóór het op

1 november

1944 een nieuwe

bestemming kreeg

en werd gebruikt

om collaborateurs

op te sluiten.

•.• Vichy op 22 juni 1940 echter de capitulatie tekent, komen de weinige Duits gevangenen vrij. Het kamp doet aanFranse en buitenls ondse vluchten voor Franse en buitenlandse vluchtelingen, meer bepaald anti-Franquisten van de jetirada uit debezette zone. Tussen 29 januarien 8 februari 1939, ha de ondergang van de Spaanse republiek, vluchten meer dan 2000 Spanjaarden voor het depen van Franco en belanden het departement Indre. De prefectuu verdeelt ze over zeven centra. Een deel van de vluchtelingen gaat terug naar Spanje, aangespoord door de Frans Een oroot aantal blijft echter liever in Een groot aantal bijft echter liever in Frankrijk. Bij de exodus van juni 1940 zijn ook vluchtelingen betrokken die deze verblijfplats. Het ris deze verblijfplaats. Het regime va vichy biengt ze dan sanen in een enke door de politie.
In juli 1942 verandert vervolgens de bestemming van het kamp als gevolg van de akkoorden tussen Karl Oberg, baas van de SS in Frankrijk, en René politie ot, sichy-regim poite onding het quet verbindt zich ertoe de buitenlandse Joden in heel Frankrijk aan de Zuid, ins over te leveren. Voor de zone zuid, inde-der-Loie, valt de kndre, Che en Indre-et-Loie, valt de keuze op het kamp'

In augustus 1942 organiseert de Vichy regering een grote razzia tegen buitenlandse Joden uit de vrije zone, en gebruikt Douadic als verzamel- en sann aangehouden tijdens de razzia'sin Indre tussen 64 and Dar wo d ze ' Daar worden ze gesorteerd. Wie voor deportatie in aanmerking komt, word gescheiden van de enkelingen die worden gespaard, en overgebracht naar het kamp van Nexon (Haute-Vienne), het ver. Van daruit ver de regio Limoges. Van daaruit vertrekken ze naa Drancy en vervolgens naar Auschwitz. Op 26 oktober 1942 wordt Douadic bovendien "hergroeperingscentrum van de Israèleten met het oog op hun overbrenging naar de bezette zone' en krijgt het aansluitend een drievoudige functie. Vanaf 1 januari 1943 hangt he Socian át de Service du Contrôle Social des Ltrangers (Dienst voor de sociale controle van buitenlanders) en herbergt het niet enkel Joden meer. Len nieuwe razzia tegen de Joden vind plaats vanaf 23 februari 1943 in Indre en een andere in maart 1944. Ook dan doet kamp. (Barlet 2011).
In de lente van 1944 vinden de laatste deportaties plaats, discreter en geval per geval. De allerlaatste konvooie car Non en Drancy worden samengesteld. Vanaf sioktober 1944 is Doude bevijding dot de site nog dient de bevijding doet de site nog dienst als depot voor clandestien nateriaal dwijnet Verzet. Na de Bevrjaing verdwijnen het selecticcontrum en het herger tatie. Tot oktober 1944 blijt enkel he opvéscentrum van de Controle Socia voor Duitse gevan. Het dient weer der Din senang bewalt door de r.r.., en wordt dan departenentaa diewerden ano 1945. Tot slot worden de barakken per opbod ver acht de norde de hectaren van het kanp woren tere de De laars, die de natuur lieten begaan. De latste overblijselen zijn de afgelopen jaren verdwenen. Het verleden van Donarist, heid. (Le Berre 2015)

\section{EEN WERK TEN DIENSTE VAN}

\section{DE GESCHIEDENIS EN DE}

Het heeft lang geduurd eer het 'Frankrijk van de kampen' opgeno'Frankrijk van de kampen' opgenopublicatie van hectale geheugen. De Paxton over La France de Vichy ber Paxton over La France de Vichy, begin jaren zeventig (1972 voor de onghe uitgave in het Engels, 1973 voor de Franse vertaling), vormde zonder de Het was wel zo dat de impijk keepunt. letwas wo zo dat de injoctervan pas leidde het woks tot wa jaren ne leidde het boek tot wat men de "paxto- en kan noemen. (Peschanski 2002a,

Het kamp van Douadic werd na de evrijding volledig gedemonteerd. De 列 cestemming . Een van de conn nieuwe deed dienst als stal in een morue in de buurt van het voormalige La Nouvelle République, 1/02/2015). Oak Ook al staat er op de site vandaag geen Inventaire général du pat, och heeft de het kam het kamp Doulde geinnentariseerd naar aanleiding van een fotografische

De historiografie en de herinnering hebben de handen in elkaar geslagen om het kanp van Douadic uit de vergetelheid te halen. In 1994 heeft Jacques Blanchard belangstelling gekregen voor dicht bij de demarcatielijn. Hije, daar dicht bij de demarcatielijn. Hij had eerover herzet men maquis van de Lim ma hij was door ‘het mysterie tieve was de warin de tieve stilte waarin de activiteiten van die (Blanchard 1994 flaptekst), hefthijeen lijvigdossier mettekstent, heeft hij een (judenten (dudos) de deportatie van de Joden in het depar-
tement Indre. Zo stelde hij vast:

Niet eens een gedenkplaat aan de rand van het kamp waar vandaag een paar koeien grazen. [.... Maar misschien geeft de informatie in dit werk wel aanleiding daar. (Blachas 1994 , fapteks)

Herbert Goetz, een Jood uit de streek van Frankfurt die het land ont- 


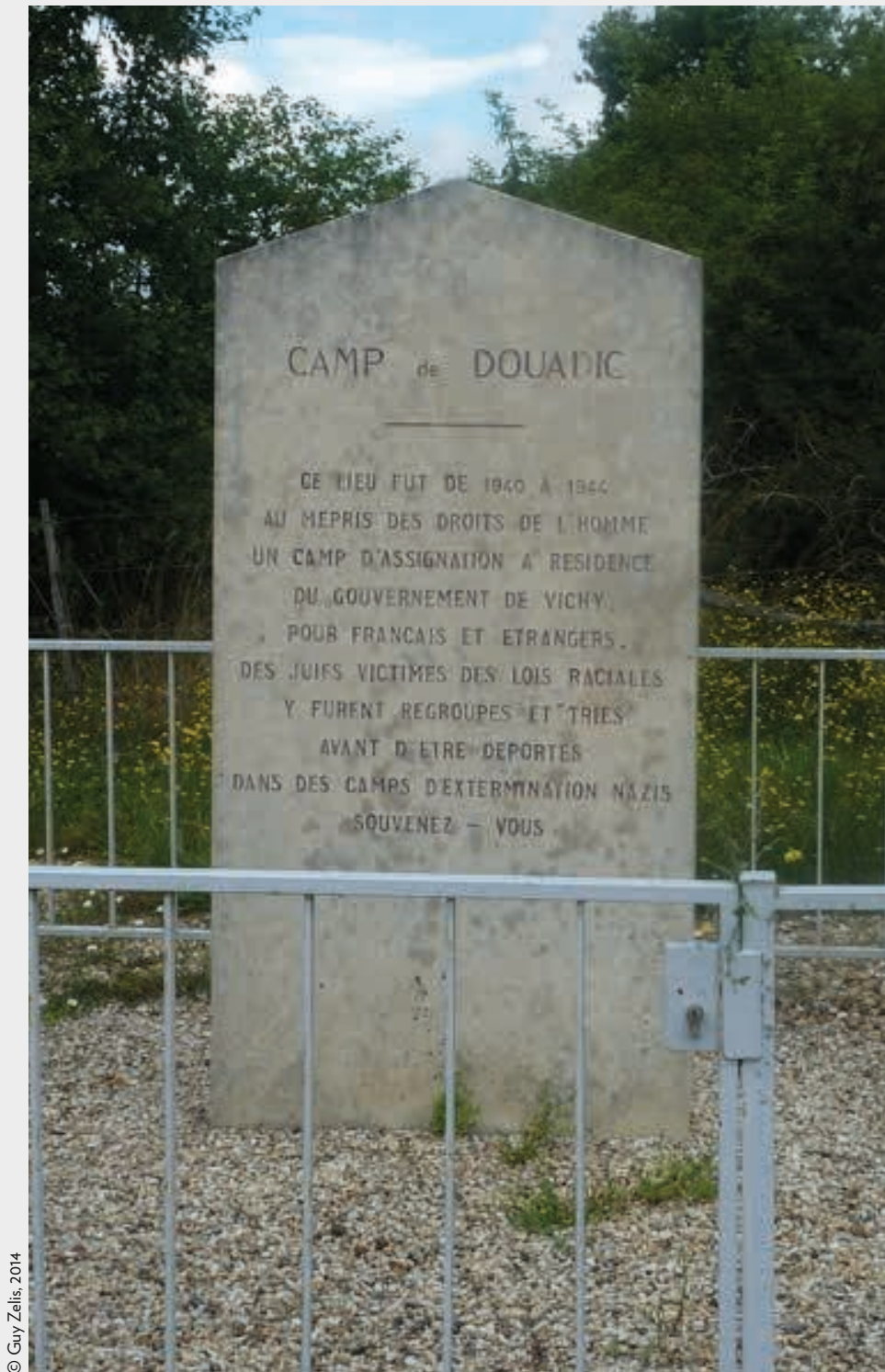

$\triangle$ De gedenksteen, opgericht in 1995

$\bullet$ vluchtte in 1936-1937, is een van de eersten die na de razzia van 26 augustu ran in kamp van Douadic leert kennen. Hij ontsnapt aan de deportatie en neent van de gevangenen van Douadic onder de aandacht te brengen. Met de hulp van het gemeentebestuur en voormalige gedeporteerden en weerstanders rich ij in 1995 een gedenksteen op tegenkamp lag.

Philippe Barlet, directeur van het Centre départemental de documentation pédagogique de l'Indre (pedagogisch documentatiecentrum van het epartement Indre), is samen met de cineast Jacques Merlaud begonnen aan de reconstructie van bedolven en gedeelde (zowel in de betekenis van gemeenschappelijk als gescheiden) herinneringen. Het resultaat van dat werk is te zien in de film La Nasse (2006). De makers hebben zich gebaseerd op een uitzondenlike verzameling van docu. Zenten ze een film van vier minuten die Jane Billard, maatschappelijk werkster en verpleegster in het kamp van Douadic, opnam tussen april en augustus 1943 deen 8 ikten zanera het kamp het kamp, genomen door Jane Billard en verschillende andere mensen, en leden van het kamp en voo kaderleden van het kanp en voornalige gevangenen zoals Herbert Goetz. Tot en Jean-Luis Laubrybelaj rijkatheen Jean-Louis Laubrybelangrijk archieon sterk, Dehelijkvan den verschillen sterk, afhankelijk van de getuigen en en edvarter overlevende gevangenen en gedeporteerden, Joodse gevangenen, leidinggevend personeel, inwoners van met de a che

De herinneringen botsen omdat het standpunt, het tijdsvak, de duur, de on plaats zelf niet op dezelfde manier werden beleefd en aangevoeld. Ook dat is een element van de geschiedenis van het kamp van Douadic (Me rekening moeten houden. ud \& Barlet 2006).

Guy Zelis

(Université catholique de Louvaì, Louvain-la-Neuve Vertaling uit het Frans: Rita Roggen

$\checkmark$ Philippe Barlet, Les camps et la déportation des juifs dans P'Indre. Douadic - Montgivray - La Vernusse, 1940-1944. Textes et $\triangle$..-. 'Camp de Douadic durant la Seconde Guerre mondiale', AJPN, 2011, http: //www.ajpn.org/internement-Camp-deDouadic-65.hthl (website van de Anoniemen, Rechtvaardigen geraadpleegd 26 november 2017).

$\diamond$--- \& Jacques Merlaud, La Nasse. Douadic, 1942-1945,

$\diamond$ Jacques Blanchard, Le camp de Douadic, centre de triage avant déportation et centre $n^{\circ} 11$ bis du Service social des étrangers, 1939

$\Leftrightarrow$ Jean-Sébastien Le Berre, 'Douadic: le camp oublié, La Nouvelle actu/douadic-le-camp-oublie (geraadpleegd 26 november 2017).

$\diamond$ Jacques Merlaud \& Philippe Barlet, 'Douadic ou la mémoire 2006, http://wwwcrndp fr/crdp-orleans-tours/fileadmin/userupload/Atelier_36/Images_Philippe_Barlet/Presentation_du_film_ La_Nasse_2006.pdf (geraadpleegd 26 november 2017)

$\diamond$ Denis Peschanski, La France des camps. Línternement, 1938: Gallimard, 2002a.

$\widehat{A}$---, 'Communistes, Juifs, collabos... La France des camps',

$\diamond$ Josiane Sodigné-Loustau, 'Laccueil des réfugiés civils espagnols l'histoire de notre temps 44, 1996, 42-47.

$\rightarrow$ Meer weten

$\diamond$ http://www.culture.fr/Ressources/Moteur-Collections: zoekrobot op de website van het Franse Ministerie van Cultuur. Whe de termen 'Douadic' en 'kamp' invoert, krijgt een aantal 